\title{
CONF-9410189--7
}

UCRL-JC-117092

PREPRINT

\section{Precision Micro Drilling with Copper Vapor Lasers}

\section{RECEIVED \\ NOV - 31995 \\ OSTI}

J. J. Chang, M. W. Martinez, B. E. Warner,

E. P. Dragon, G. Huete, and M. E. Solarski

This paper was prepared for submittal to the 13th International Congress on Applications of

Lasers and Electro-Optics

Orlando, Florida

October 17-20, 1994

September 2, 1994

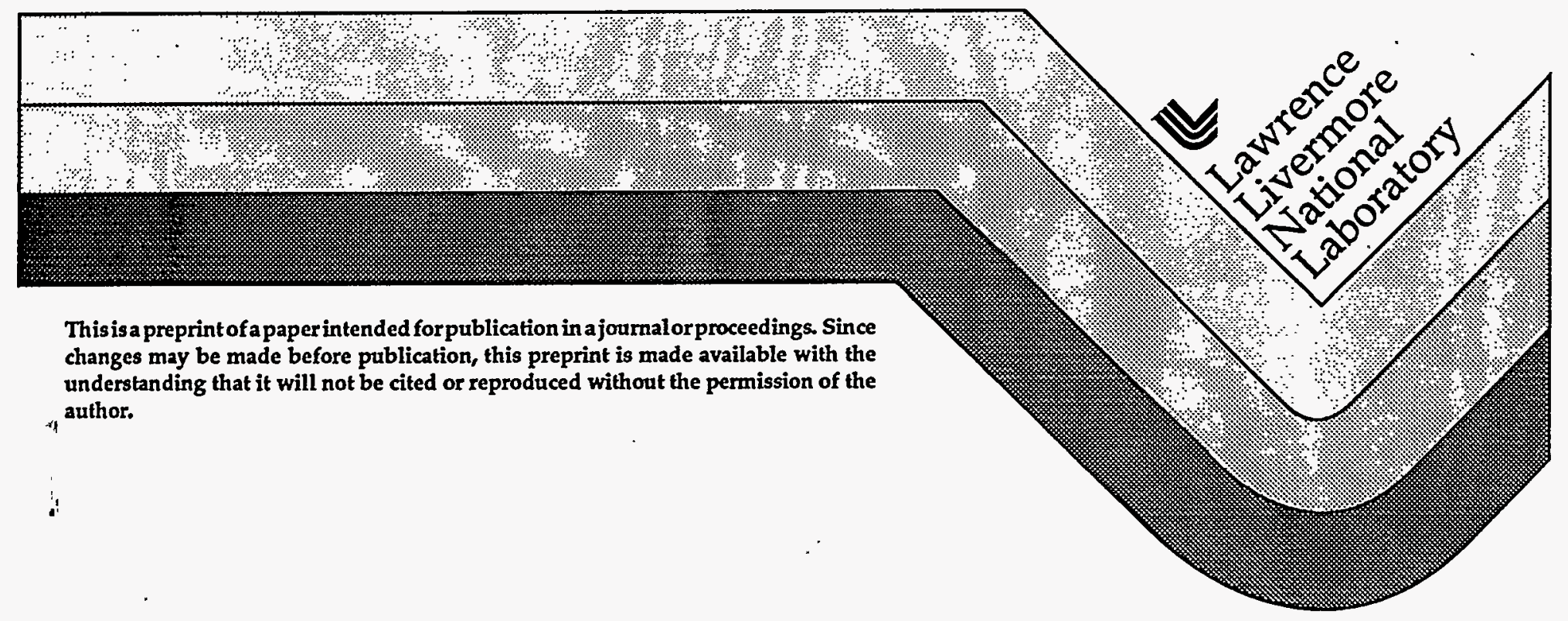

DETRBUTION OF THES DOOUNENT IS UNLMTTED , NW

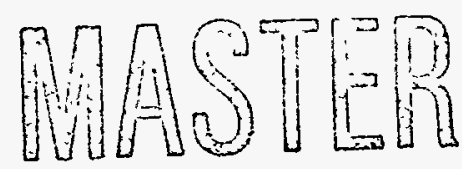





\title{
Precision Micro Drilling with Copper Vapor Lasers*
}

\section{J. J. Chang, M.W. Martinez, B. E. Warner, E. P. Dragon, G. Huete, and M. E. Solarski}

Lawrence Livermore National Laboratory

P. O. Box 808 , L-464

Livermore, CA 94551

\begin{abstract}
We have developed a copper vapor laser based micro machining system using advanced beam quality control and precision wavefront tilting technologies. Micro drilling has been demonstrated through percussion drilling and trepanning using this system. With a $30 \mathrm{~W}$ copper vapor laser running at multi-kHz pulse repetition frequency, straight parallel holes with size varying from 500 microns to less than 25 microns and with aspect ratio up to $1: 40$ have been consistently drilled on a variety of metals with good quality. For precision trepanned holes, the hole-to-hole size variation is typically within $1 \%$ of its diameter. Hole entrance and exit are both well defined with dimension error less than a few microns. Materialography of sectioned holes shows little (sub-micron scale) recast layer and heat affected zone with surface roughness within 1-2 microns.
\end{abstract}

\section{INTRODUCTION}

Laser micro machining has found expanded use in automobile, aerospace, and electronics industries because of the possibility of making small and unique structures that are difficult to achieve with conventional methods. Recently, many new applications with economic implications have also been identified, such as fabrication of micro mechanical components $[1,2]$ and micro processing in microelectronics [3,4,5]. Despite these developments, the advancement of laser drilling has been slow even after decades of use.

Laser drilling has been widely used in industry because of its high production rate, ability to rapidly vary hole size, ability to drill holes at shallow angle, and ability to drill traditionally hard to work materials such as ceramics and composite materials. Most laser drilling systems are based on $\mathrm{CW}$ or long pulse $\mathrm{CO}_{2}$ and YAG laser systems $[6,7,8]$. Material removal with these lasers are mostly through melt expulsion. This material removing mechanism normally leads to poor dimensional control and sizable recast layer with micro cracks on the side wall of drilled holes. The

\footnotetext{
- This work was performed under the auspices of the U.S. Department of Energy by Lawrence

Livermore National Laboratory under contract No. W-7405-Eng-48.
} 
strong plasma-beam interaction at longer wavelength (i.e., $10.6 \mu \mathrm{m}$ ) due to inverse bremsstrahlung also makes the material removal during laser drilling less controllable. In addition, the reduced focusibility of the infrared laser beam makes it more difficult to produce micron scale holes with large hole aspect ratio (i.e., hole depth to diameter). YAG laser systems have less pronounced plasma-beam interaction and shorter wavelength (i.e., $1.06 \mu \mathrm{m}$ ), but typically suffer from poor beam quality because of heating of the laser rod.

These issues have prevented the advancement of high-quality precision laser drilling. Lately, because of the advancement of low power waveguide excimer lasers and frequency-quadrupled Nd-YAG lasers, precision micro drilling has been demonstrated on non metallic materials $[1,2,4]$. Precision micromachining on metals, however, still has not been realized because of the problems of large dimensional error and large hole taper [5,6,7], in addition to the formation of recast layer and heat affected zone. Although trepanning technique has been applied to improve the accuracy of laser micro drilling, its hole aspect ratio was mostly limited to less than $1: 1$.

Recently, we have developed a new laser micro drilling technique based on a near-diffraction-limited copper vapor laser (CVL) and a precision wavefront tilting technology. High-aspect ratio straight holes characterized by smooth side wall with negligible recast layer have been consistently produced. The use of precision wavefront tilting technology also greatly reduces the hole size and roundness error, typically to less than a few microns. This paper reports the new copper laser based micro machining technology and its implementation in precision micro drilling.

\section{LASER MICRO MACHINING SYSTEM}

Focusability of a laser beam is one of the most important characteristics of a laser micro machining system. In order to produce a small, circular laser focus spot with a reasonable focal depth (20-30 times the spot size), the laser beam needs to be near diffraction limited with wavelength in the visible or UV range. To minimize the heat affected zone, the duration of laser pulse needs to be less than a few microsecond such that heat conduction to the material during drilling is negligible. Multi-kHz operation is preferred to remove the material in a more controllable fashion, such that material removed during each pulse is small while the processing speed is maintained because of high pulse rate. A CVL, with its high repetition frequency $(4-20 \mathrm{kHz})$ and short output pulse (30-100 ns) in the visible spectrum, has been considered an ideal tool for laser micro machining $[9,10,11]$ However, the difficulties in control of CVL beam quality and in optimization of processing parameters have prevented it from generating repeatable high precision result. Our recent development in medium-power high-beam-quality CVL and precision wavefront tilting technology has gradually revealed its potential in laser precision micro fabrication.

The schematic of our copper laser based micro machining system is illustrated in Figure 1. An injection controlled copper laser oscillator [12] with near-diffraction-limited beam quality is used in this system. A power-in-the-bucket measurement indicates $-73 \%$ of the laser output is within diffraction limited beam divergence. This CVL beam quality is thus approximately 1.1 times diffraction limited based on Strehl ratio. The laser is designed to be operated between $4-9 \mathrm{kHz}$ for various material processing requirements. This laser generates about $30 \mathrm{~W}$ output at wavelengths of $511 \mathrm{~nm}(60 \%)$ and $578 \mathrm{~nm}(40 \%)$. The self-terminated CVL used in our system typically has a pulse duration of 50-70 ns. The laser beam is focused by achromat on the working piece that typically generates a diffraction limited spot size. As shown in Figure 1, a precision two- 
axis scanning mirror is used to tilt the laser wavefront before passing through the achromat with an angular resolution better than $5 \mu \mathrm{rad}$. This scanning mirror is equipped with a feedback loop to compensate for hysteresis effects. The beam scanning frequency on the work piece can be varied from $1 \mathrm{~Hz}$ to about $100 \mathrm{~Hz}$ depending on application requirement. A camera is used to examine the progress of material processing on the working piece based on reflected : laser light.

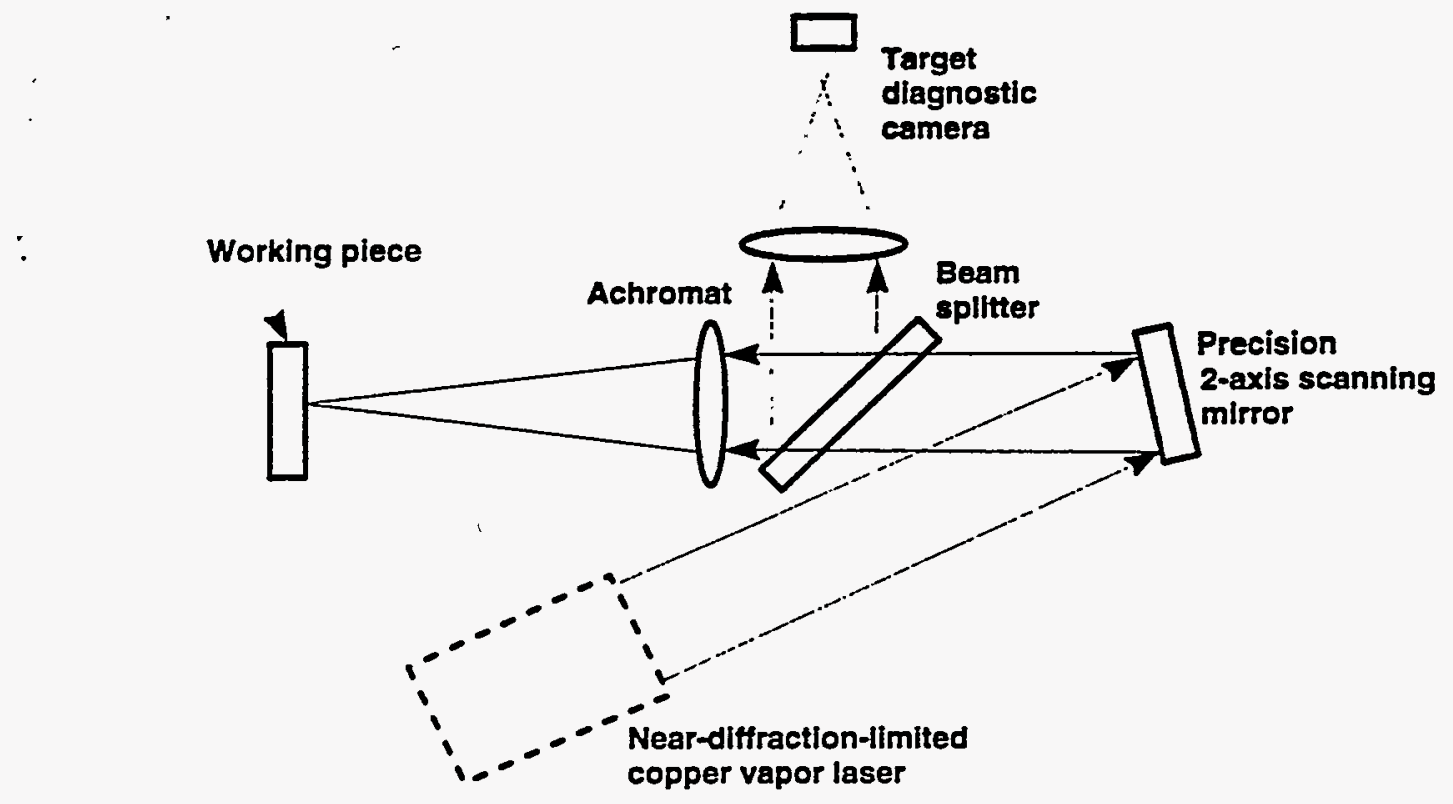

Figure 1. The schematic of a CVL micro machining system.

\section{CVL MICRO DRILLING}

Because of the wide spread use of $\mathrm{CW}$ or long pulse $\mathrm{CO}_{2}$ and $\mathrm{Nd}$ :YAG lasers in industries, material removal in conventional laser drillings are mostly through melting and expulsion owing to low laser peak power. Melt removal with the assist of a gas nozzle, although is satisfactory for some laser machining applications, represents a major technical issue in micro machining because of its highly uncontrollable machining nature. Poor drilling repeatability and sizable recast layer are thus typical in laser drilled holes. These issues worsen as the holes become smaller, resulting in a very limited application for laser based micro drilling. To overcome these problems, the main mechanism for material removal needs to be predominately laser ablation with little melt formation. The material removal in this fashion can then be well controlled within the area illuminated by laser light. The successful demonstrations of laser micro drilling on non-metallic material by UV lasers $[1,2]$ are typical examples of the advantageous laser ablation process. UV laser ablation on most non-metallic materials is basically a non-thermal process by breaking structure bond without melting (photolytic). Laser ablation in metals, although achievable with higher laser peak power, is still a thermal process that includes rapid melting and vaporization of material illuminated by laser beam. The condensation of ablated material on the surface also complicates this process, especially for high-aspect ratio machining. A more sophisticated processing control is thus required for high quality micro drillings in metals. 


\subsection{CVL Percussion Drilling}

In CVL percussion drilling, a stationary laser beam is used to drill through a stationary work piece. Straight parallel holes with aspect ratio better than $40: 1$ have been repeatedly produced in a variety of steels. Figure 2 shows a section of three 20-25 micron diameter holes percussion drilled on stainless steel ( $1 \mathrm{~mm}$ thickness). Because of the material removal in this case was mostly through laser ablation, these holes show no measurable heat affected zone and the hole quality is distinctively superior than those drilled with long pulse $\mathrm{CO}_{2}$ and Nd:YAG lasers. Smaller hole sizes can also be achieved using lower laser power or faster focusing optics, but this also reduces material penetration with the possibility of generating tapered holes. Since the coupling between the side wall of a drilled hole and the laser beam is very poor due to high incidence angle, our experience indicates that the laser peak power on the hole entrance must be more than a few $\mathrm{GW} / \mathrm{cm}^{2}$ to avoid hole taper.

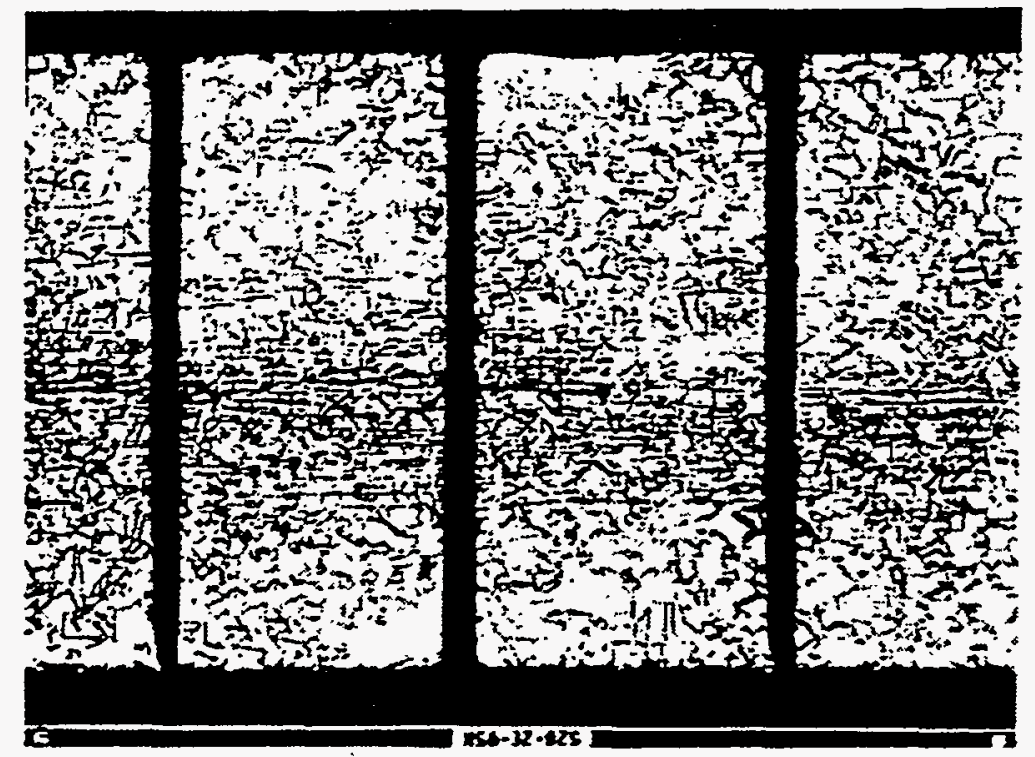

Figure 2. Section of CVL percussion drilled holes on a $1 \mathrm{~mm}$ thick stainless steel with hole diameter 20-25 microns. These holes show no measurable heat affected zone. Note that the minor taper on the hole bottom was actually caused by section error. The hole sizes measured on the top and the bottom are less than $10 \%$ different.

Assist gas was not found to be essential in CVL micro drilling, but there is evidence that oxygen increases drilling speed due to exothermic reactions. Although straight holes free of recast layer can be produced by a simple CVL percussion drilling at a fairly fast speed, the hole dimensional control and hole repeatability are generally not satisfactory for high precision applications. Typically a tolerance of hole size and roundness of approximately $10 \%$ of its diameter is expected. Higher precision micro drilling must be accomplished by laser trepanning. 


\subsection{CVL Precision Trepanning}

Laser trepanning has long been applied in industry to either improve the hole accuracy or to generate large holes, mostly for hole aspect ratio less than 1:1. Precision micro trepanning for higher aspect ratio holes has rarely been accomplished because of difficulties in material penetration and removal. In our investigation, laser trepanning is achieved by periodically tilting the X-Y scanning mirror such that the laser spot generates a circular pattern on the work piece. A typical laser beam scanning pattern is illustrated in Figure 3a that shows a circle with diameter of 180 microns. The resulting laser burn pattern on the work piece is shown in Figure $3 \mathrm{~b}$ that illustrates a well defined kerf ablated by a CVL focus spot. Note that the coloration along the side of the kerf was burned by the side lobes of the far-field spot.

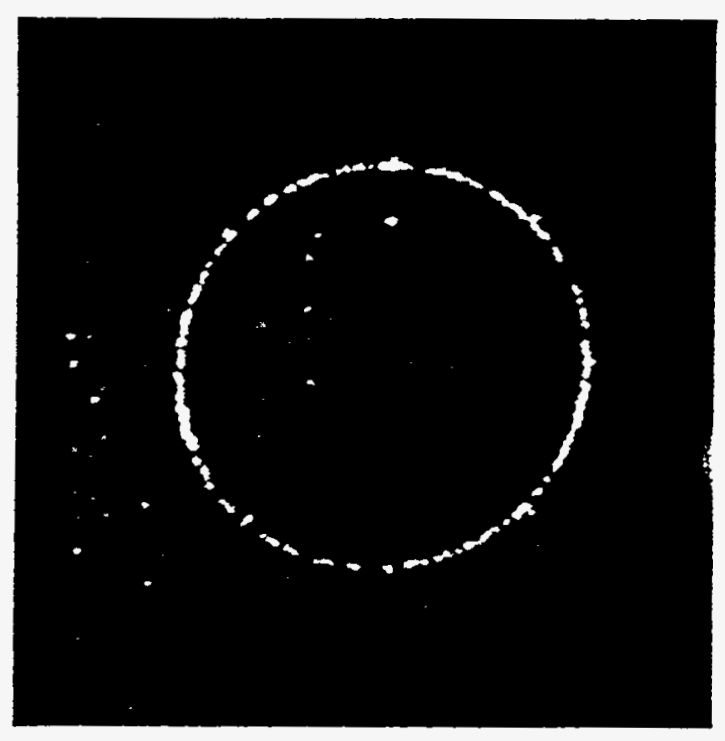

(a)

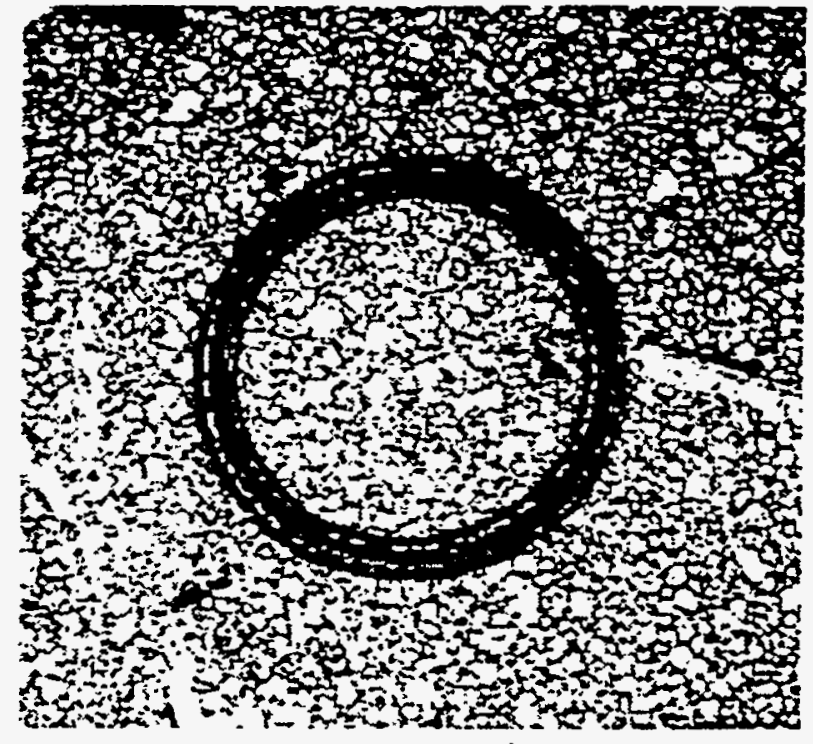

(b)

Figure 3. (a) A circular laser scanning pattern ( 180 micron diameter) for micro trepanning. (b) The resulting laser burn mark on the working piece.

\subsubsection{Control of hole geometry and effect of beam polarization}

Figure 4 illustrates three CVL trepanned holes with 185 micron diameter on a $1 \mathrm{~mm}$ stainless steel. The sample was ultrasonic cleaned after drilling without additional post processing. Minor edge erosion with depth less than 10 microns was found on the laser entrance side as shown in Figure 4a. However, materialographic examination of sectioned holes indicates the material underneath of this area was not affected. The holes on the laser exit side, shown in Figure $4 \mathrm{~b}$, demonstrate extremely well defined circular hole pattern without erosion. Measurements indicate that both the entrance and exit holes have a roundness error of about 5 microns caused by various mechanisms.

It is obvious that the geometry of the entrance hole is predominately determined by the laser scanning pattern and the shape of a laser spot. Because of the existence of some residue hysteresis. of our scanning mirror system, the laser scanning pattem shown in Figure 3 actually has a $-2 \%$ 
roundness error that explains the dimension error of the entrance holes shown in Figure 4a. On the other hand, the geometry of the exit holes, although primarily controlled by the laser scanning pattern, is also strongly affected by the polarization state of the laser beam. Because of the difference in surface absorption between $S$ and $P$ polarized beam, especially at high incident angles, the laser beam material removal is more effective along the beam polarization because of its more effective coupling with the side wall. A polarized beam may thus lead to an elongated exit hole. On the material entrance surface, the laser-material coupling is the same for both $S$ and $P$ polarization because of the normal incidence angle. The geometry of a entrance hole is thus not affected by the state of beam polarization.

Repeatability of hole dimension has been significantly improved with CVL trepanning as demonstrated in Fig. 4. The variations of hole size and shape were almost impossible to measure based on our microscope measuring system. This striking improvement on hole repeatability is believed to be mainly due to the fact that laser trepanning not only performs material removal during the initial drilling phase, but also engages in material trimming and side wall polishing during the later drilling phase.

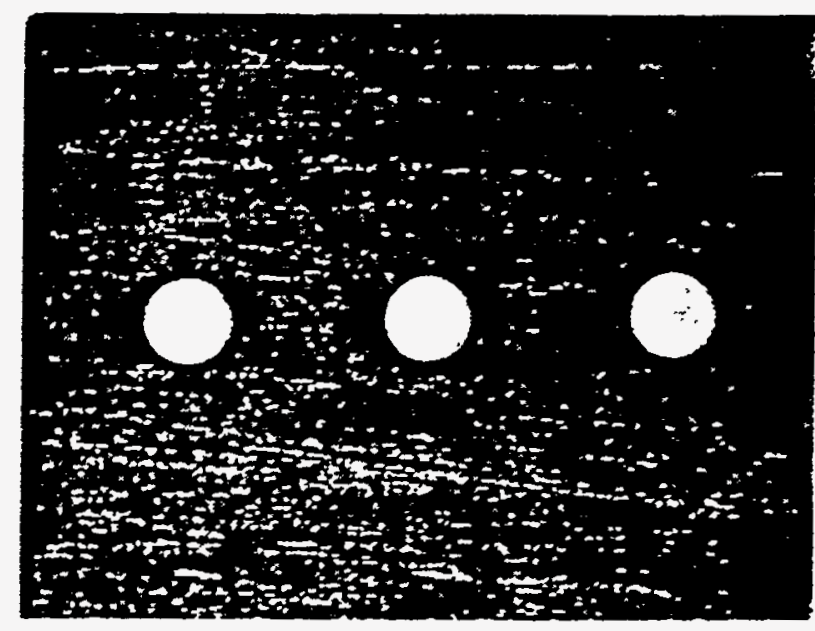

(a)

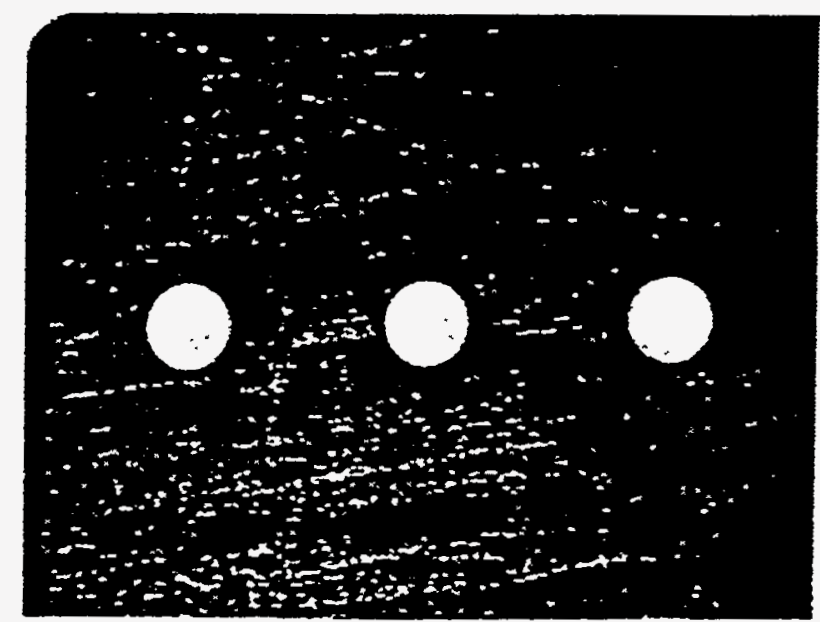

(b)

Figure 4. Precision laser trepanned holes on a $1 \mathrm{~mm}$ thick hardened steel with hole diameter of 185 microns. (a) Laser entrance side. (b) Laser exit side.

\subsubsection{Side wall of micro trepanned holes}

A section of three trepanned holes is illustrated in Figure 5(a). It shows fairly straight side walls with surface roughness measured within 1-2 microns (i.e., peak to valley) which is comparable to the low end of a grinding finish. A minor curvature on the side wall was caused by the caustic surface of the focused laser beam and can be corrected with a longer focus lens. Detailed examination of the hole section reveals that the recast layer and heat affected zone are minimized to a non-measurable level (i.e., sub-micron) as illustrated in Fig. 5(b). Figure 6 is a SEM picture of a CVL trepanned hole which clearly shows an unaltered grain structure on the side wall as a consequence of effective laser ablation process during CVL trepanning. 

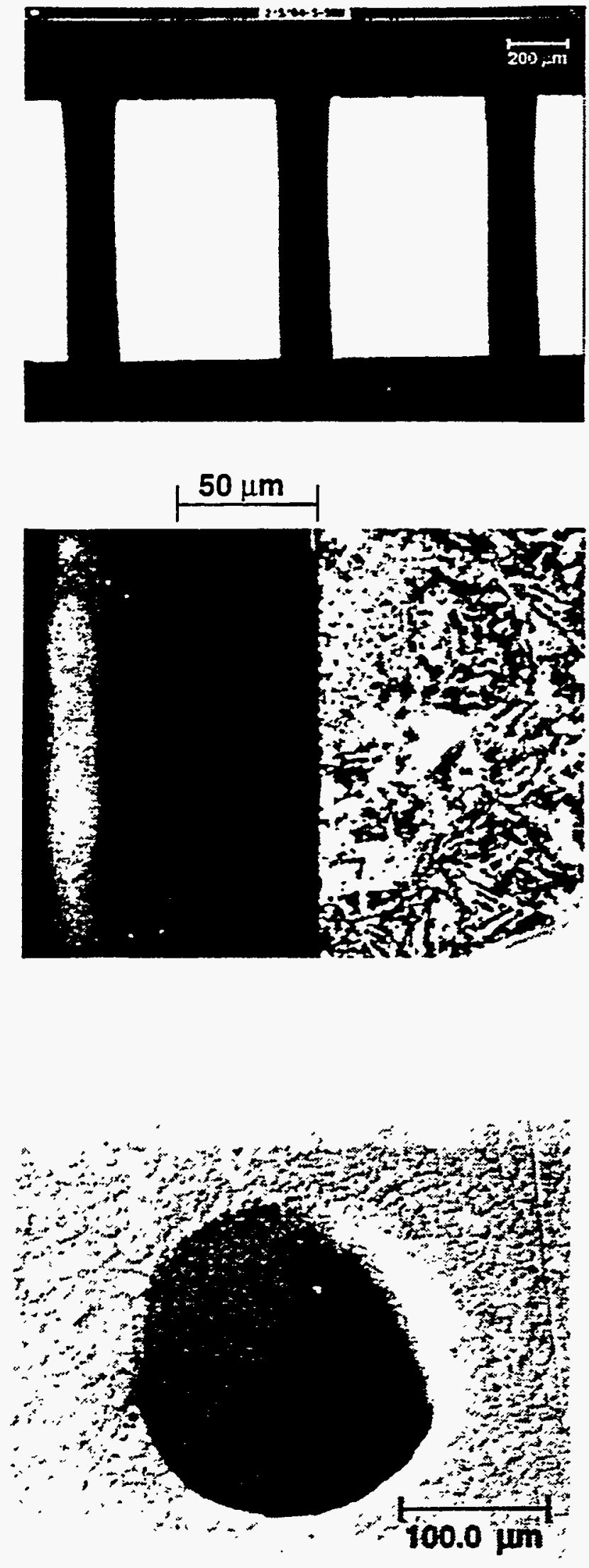

(a)

(b)

Figure 5. (a) A section of three CVL trepanned holes on a $1 \mathrm{~mm}$ thick hardened steel. (b) Materialographic section shows good surface finish with no heat affected area.

Figure 6. A SEM picture of CVL trepanned hole on stainless steel. Because of the effective CVL ablation process, the material grain structure on the side wall is basically not affected as shown. 


\subsubsection{CVL trepanning of non-circular holes}

In addition to circular holes, we have demonstrated non-circular holes with various geometries on a $1 \mathrm{~mm}$ thick stainless steel, as illustrated in Figure 7. These holes were cut by modifying the scanning pattern of the trepanning system to draw the desired shape on the target. Hole aspect ratio higher than 10:1 with no taper has been achieved with these non-circular trepanned holes. The corner rounding effect shown in Fig. 7 becomes more severe as hole size reduced to smaller than 100 micron. This effect primarily arose from the size of the CVL far-field beam footprint. It can be improved by using faster focus lens when smaller hole aspect ratio is required. This demonstration of non-circular micro holes with high aspect ratio reveals the great potential in laser trepanning applications and may have significant impact on engineering design that was traditionally limited to circular holes.

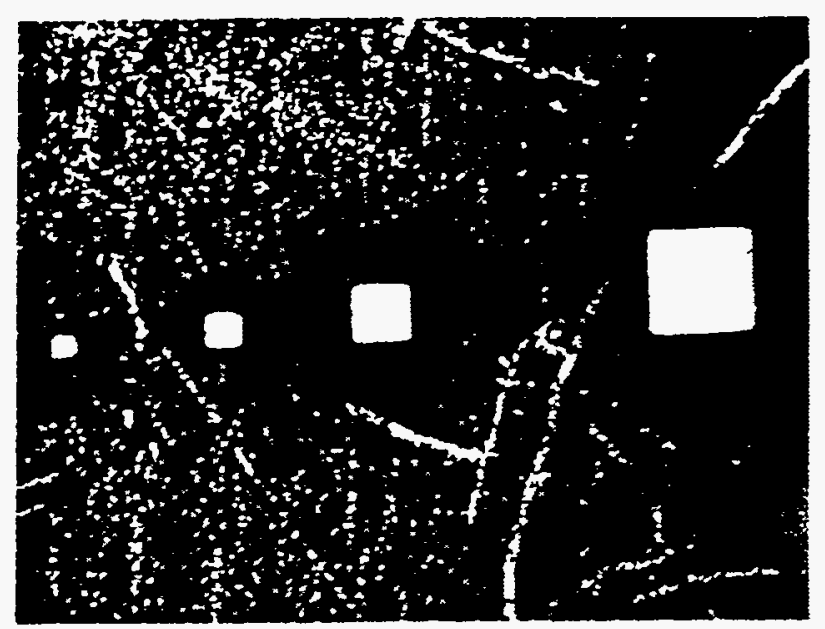

(a)

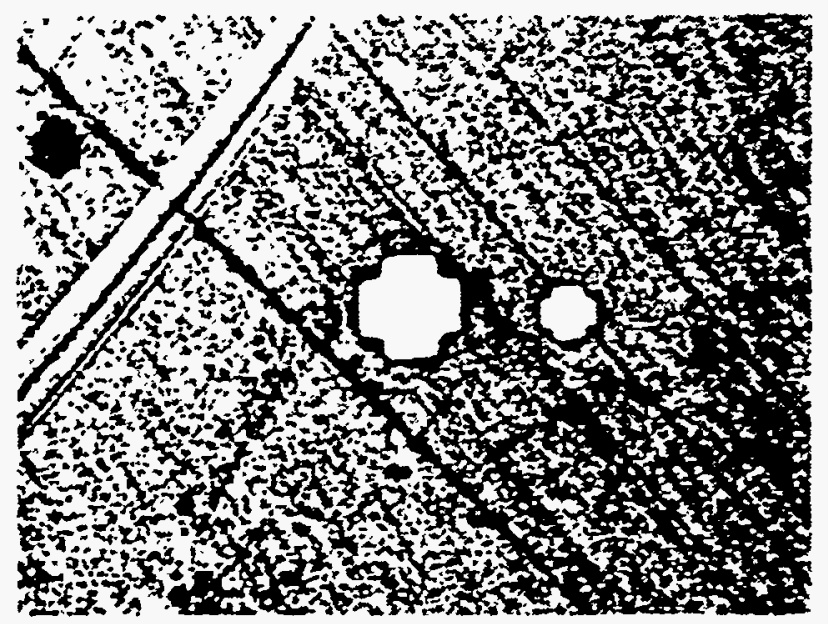

(c)

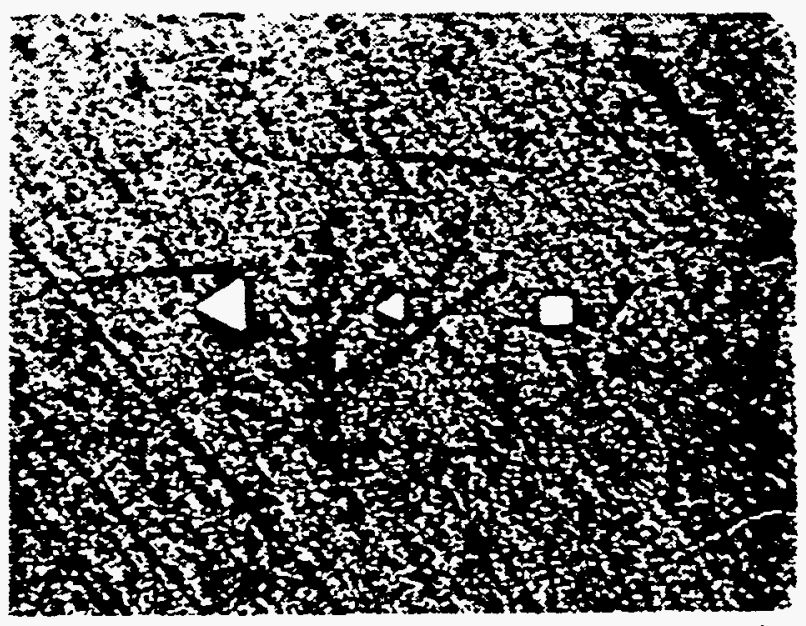

(b)

Figure 7. CVL trepanned holes on a $1 \mathrm{~mm}$ thick stainless steel that show a variety of hole geometries can be drilled with aspect ratio larger than 10:1. Hole dimensions from left to right are (a) $80 \mu \mathrm{m}, 110 \mu \mathrm{m}, 190 \mu \mathrm{m}, 350 \mu \mathrm{m}$, (b) $156 \mu \mathrm{m}, 84 \mu \mathrm{m}, 90 \mu \mathrm{m}$, (c) $350 \mu \mathrm{m}$, $180 \mu \mathrm{m}$. 


\section{CONCLUSION}

CVL micro drilling has been demonstrated through percussion drilling and trepanning us$\because$ ing LLNL developed high beam quality CVL and precision wavefront tilt technology. Straight holes with sizes varying from 20 microns to 500 microns have been consistently drilled with hole aspect ratio up to $1: 40$ on a variety of steels. Materialographic sections of the drilled holes indicate little heat affected zone or recast layer because of an effective laser ablation process owing to the short pulse and high peak output power $\left(10^{8}-10^{10} \mathrm{~W} / \mathrm{cm}^{2}\right)$ of CVL's.

CVL percussion drilled holes typically show a hole dimension error of $10 \%$ of its diameter. When higher precision is needed, CVL trepanning can be applied to improve the dimension error to less than a few microns. The repeatability of trepanned holes is excellent when the drilling parameters, which are laser power, scanning frequency, scanning geometry, focus position, laser polarization, and processing time, are well maintained. We have demonstrated trepanned holes with size variation within $1 \%$ of hole diameter. Surface roughness inside trepanned holes was measured within 1 to 2 micron peak to valley. This good surface finish in trepanned holes is primarily because of laser trimming and polishing accompanied with trepanning. Based on the authors'

knowledge, the micro trepanned holes we machined are the first demonstration of high-precision high-quality laser hole drilling on metal with greater than 10:1 hole aspect ratio and excellent repeatability.

This CVL trepanning system represents a great potential in laser precision micro drilling. Non-circular holes have been drilled by simply changing the laser scanning pattern. The hole quality drilled by this laser micro machining system was found to be comparable or better than holes drilled by EDM (i.e., Electrical Discharge Machining). With the flexibility in hole geometry and size, and scaleability to higher speed, this micro machining system offers a superior technique to EDM machines which are currently widely used in industry.

\section{REFERENCES}

1. E. Wiener-Avnear, "Laser cut microscopic paths with major potential," Laser Focus World, pp. 75-80, July, 1993.

2. C. Paul Christensen, "Waveguide excimer laser fabrication of 3D microstructures," SPIE, Vol. 2045, pp. 141-145, 1994.

3. M. Meunier, M. Tabbal, M. Suys, R. Izquierdo, A. Yelon, E. Sacher, and S. Poulin, "Excimer laser-induced metallization for Si and GaAs Microelectronics," SPIE, v. 2045, pp. 84-90; 1994.

4. J. Hobbs, "Electrics makers switch to precise micro machining tools," Laser Focus World, pp. 69-72, March, 1994.

5. A. Kestenbaum, J. D'amico, B. Blumenstock and M. Deangelo, "Laser drilling of microvias in epoxy-glass printed circuit boards," IEEE Trans. on Components, Hybrids, and Manufact., Vol. 13, pp.1055-1062, 1990.

6. S. Tam, C. Yeo, S. Jana, M. Lau, L. Lim, L. Yang, and Y. Noor, "Optimization of laser deep-hole drilling of Inconel 718 using Taguchi method," J. Materials Processing Tech. v. 37, pp. 741757, 1993. 
7. S. Takeno, M. Moritasu, and S. Hiramoto, "laser drilling by high-peak pulsed $\mathrm{CO}_{2}$ laser," ICALEO'92 Proceeding, pp. 459-468, 1992.

8. H. Treusch and G. Herziger, "Metal precision drilling with lasers," SPIE, Vol. 650, pp. 220-225, 1986.

9. R. Kupfer, H. Bergmann, M. Lingenauer, "Material influence on cutting and drilling of metals using copper vapor lasers," SPIE, Vol. 1598, pp. 46-60, 1991.

10. H. Bergmann and M. Hartmann, "Drilling of metals with copper vapor lasers," Laser Processing Proceedings, TMS Annual Meeting, Denver, 1993.

11. R. Pini, R. Salimbeni, M. Vannini, and G. Toci, "Copper vapor laser high aspect ratio drilling process on transparent materials," Presented in CLEO'92, Los Angeles, 1992.

12. J. Chang and M. Solarski, "A self-imaging injection-controlled copper laser oscillator," CLEO'93 Digest, p. 458, 1993. 
Technical Information Department • Lawrence Livermore National Laboratory University of California - Livermore, California 94551

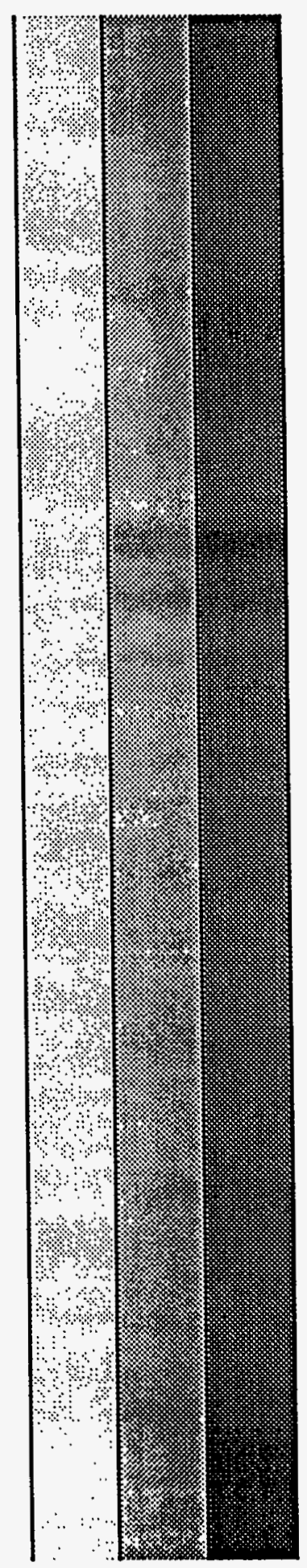

